\title{
Obsolete Computers, "Gold Mine," or High-Tech Trash? Resource Recovery from Recycling
}

\section{Introduction}

Obsolete computers contain significant amounts of recoverable materials including metals from wires and circuit boards, glass from monitors, and plastics from casings (fig. 1). For example, 1 metric ton $(t)$ of electronic scrap from personal computers (PC's) contains more gold than that recovered from $17 \mathrm{t}$ of gold ore. ${ }^{1}$ In 1998, the amount of gold recovered from electronic scrap in the United States was equivalent to that recovered from more than 2 million metric tons (Mt) of gold ore and waste. ${ }^{2}$

The amount of computer waste increases annually as electronic systems play an increasingly important role in all aspects of technology, but significant amounts of material used in the devices are not recovered. Because microchip development is so rapid (Hamilton and Takahashi, 1996), users are able, every 18 months, to purchase computers that are twice as powerful at the same price as those currently available (Jung, 1999). This cyclic trend (with its inherent surplus of old computer components) has been sustained for nearly 20 years of recent computer history. To meet consumer demand, the computer and electronics industry has become the largest manufacturing employer in the United States, representing 11 percent of the gross domestic product and growing at an annual rate of 4 percent (Porter, 1998).

The quantities and types of materials used in computer products to meet this demand are great and varied, as is the potential to recover these computers and their materials for reuse, remanufacturing, and recycling. In 1998, nearly 43 million new PC's and notebook computers were purchased by consumers in the United States; and it is estimated that in the year 2003, nearly 70 million computers will be purchased by consumers in the United States (National Safety Council, 1999).

In 1997, it was estimated that between 1985 and 2005, approximately 325 million PC's would become obsolete in the United States (Jung, 1999). In a business environment, the useful life of a PC is about 2 years, while in homes PC's are used from 3 to 5 years (Jung, 1999). Between 14 and 20 million PC's

\footnotetext{
${ }^{1}$ Based on 1 troy ounce of gold recovered for every $3 \mathrm{t}$ of electronic scrap (10.4 grams per metric ton $(\mathrm{g} / \mathrm{t}))$ and an average gold ore feed grade of $0.9 \mathrm{~g} / \mathrm{t}$ for a typical gold openpit cyanide leaching operation in Nevada with an overall 67 percent gold recovery.

${ }^{2}$ Based on a 2.7:1 waste-to-ore ratio.
}

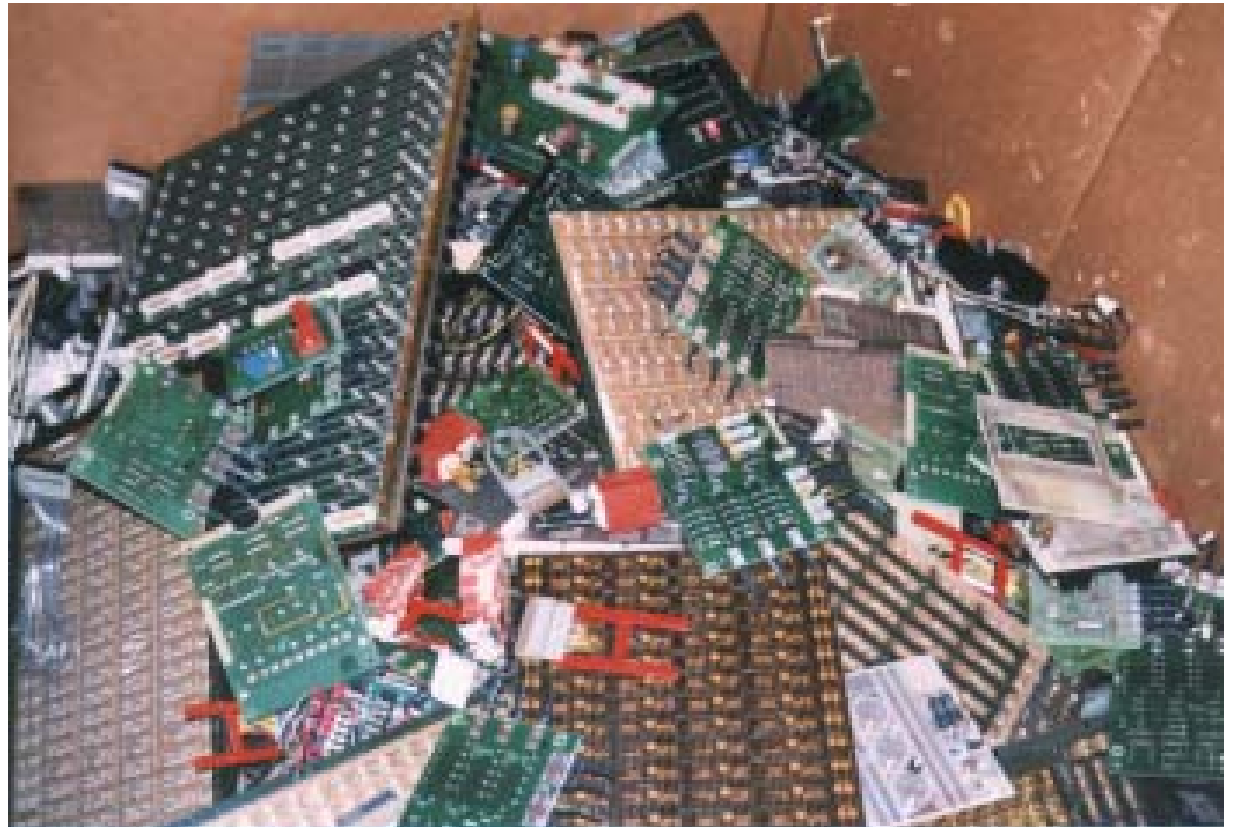

Figure 1. Circuit boards are sought after by recyclers for their metals content, especially gold and silver. Photograph courtesy of M elissa Goodrich, Recycling Today. become obsolete every year in the United States. About 75 percent of these obsolete computers are not discarded because their owners perceive them to be valuable (Goodrich, 1999); a portion of these will not be recycled. For every three computers purchased in the United States, two will be taken out of service, and this ratio is expected to increase to $1: 1$ by 2005 . It is projected that by 2005 , a total of 680 million PC's will have been sold worldwide. Of that total, it is estimated that 150 million computers will be recycled that year and 55 million computers will end up in landfills along with unreclaimed portions of the 150 million recycled computers (Hamilton and Takahashi, 1996).

\section{Recycling Flow}

Figure 2 is a generalized materials flow diagram that shows what happens to obsolete PC's and their components.

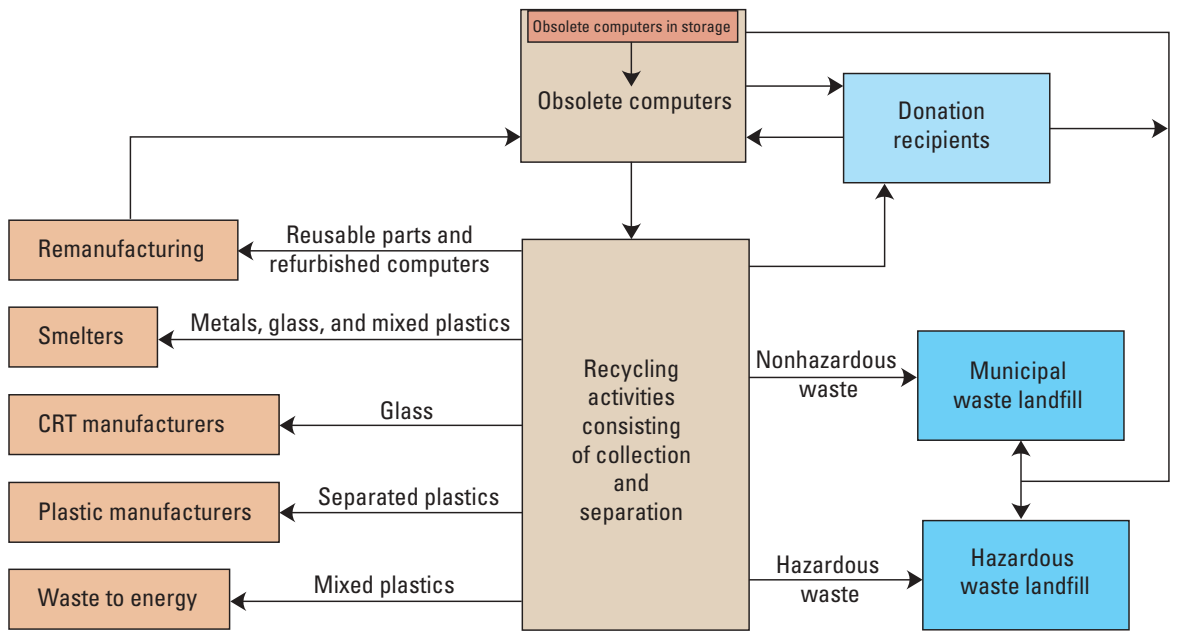

Figure 2. A generalized materials flow diagram illustrating what happens to obsolete PC's and their components. 
This figure includes

- computers that owners retain (but do not use) or donate or dispose of directly or indirectly to municipal waste and hazardous waste landfills (The U.S. Environmental Protection Agency (EPA) categorizes cathode ray tubes (CRT's) as hazardous waste, although exemptions exist for disposal of equipment generated by households and small business.);

- computers that can be refurbished and sold or donated by companies or organizations; and

- what happens to computers that can be dismantled and sold for reuse, melted and recycled, incinerated as a fuel for producing energy, and disposed of in landfills.

Computers and other electronic devices represent a large resource of potentially recoverable material. Table 1 lists selected types and amounts of material reportedly recovered in 1997 and 1998 from computer and other electronic scrap. In 1998, about 2.6 million PC's and notebook computers were recycled in the United States, and this number is expected to quadruple by 2003 (National Safety Council, 1999). Recyclers received nearly 50 percent of electronic products directly from manufacturers; about 30 percent from large companies that utilize electronics in their business; and the rest from small companies, government offices, and individuals (National Safety Council, 1999).

Some scrap is unwanted because of low precious metal content and the potentially hazardous nature of some of its materials. For example, the presence of lead in some electronic scrap prevents it from being placed in a municipal landfill. Some refiners actually have to charge as much as $\$ 1$ per pound to process the scrap because of these deleterious materials (Broughton, 1996).

Some scrap was exported to Taiwan for open burning and chemical processing; however, the Taiwanese government had reportedly become increasingly concerned about the environmental damage caused by this practice (Broughton, 1996). Chinese and other Asian consumers pay 15 to 20 cents per pound for electronic scrap on the U.S. West Coast (Goodrich, 1999). Environmental regulations are less strict (or not enforced), and labor costs are much lower in some of these countries.

\section{Metals}

The metals contained in PC's commonly include aluminum, antimony, arsenic, barium, beryllium, cadmium, chromium, cobalt, copper, gallium, gold, iron, lead, manganese, mercury, palladium, platinum, selenium, silver, and zinc. Eight of these metals (shown in bolded type) are listed as hazardous by the Resource Conservation and Recovery Act (RCRA), one of the Federal laws that control the disposition of waste in the United States. This law prohibits

Table 1.- Reported material recovered by electronics recyclers in the United States.

[In thousands of metric tons. Modified from National Safety Council (1999) and

Sean Magaan (Noranda, Inc., Micro Metallics Corp., oral commun., 1999)]

\begin{tabular}{lcc}
\hline Type of material & 1997 & 1998 \\
\hline Glass & 11.6 & 13.2 \\
Plastic & 3.7 & 6.5 \\
Metals & & \\
Aluminum & 3.9 & 4.5 \\
Steel & 14.5 & 19.9 \\
Copper & 4.3 & 4.6 \\
Combined precious & 0.001 & 0.001 \\
$\quad$ metals (gold, palladium, & & \\
platinum, and silver) & 3.1 & 3.6 \\
Other & 41.1 & 52.3 \\
\hline$\quad$ Total &
\end{tabular}

companies from incinerating some types of electronic scrap or disposing of it into municipal landfills.

Historically, recovering precious metals from electronic scrap has been one of the greatest economic incentives for the electronics recycling industry. However, in an effort to cut costs, manufacturers have gradually reduced the precious metal content in electronic products, and this trend is likely to continue (Porter, 1998). Information on the specific amounts of individual precious metals (gold, silver, and the platinum group metals) recovered is unavailable, but as much as one-third of the precious metals recovered from scrap may be gold (Sean Magaan, Noranda, Inc., Micro Metallics Corp., oral commun., 1999). The value of the $1 \mathrm{t}$ of precious metals recovered from electronic scrap in the United States in 1998 (table 1) probably exceeded $\$ 3.6$ million. This value was obtained by assuming that the precious metals recovered consisted of 60 percent silver and 40 percent gold, palladium, and platinum. The average price used to calculate the value was $\$ 5.10$ per troy ounce of silver and an average of $\$ 300$ per troy ounce of gold, palladium, and platinum. Several U.S. companies reported producing more than 1,500 troy ounces per year of precious metals from electronic scrap (Dawn Amore, National Recycling Coalition, oral commun., 1999).

Circuit boards and batteries contain most of the heavy metals, and circuit boards contain the highest precious metal values. One metric ton of circuit boards can contain between 80 and 1,500 $\mathrm{g}$ of gold and between 160 and 210 $\mathrm{kg}$ of copper (Veldhuizen and Sippel, 1994). This is 40 to 800 times the concentration of gold contained in gold ore mined in the United States and 30 to 40 times the concentration of copper contained in copper ore mined in the United States. Gold in an obsolete computer has little or no value. Like ore, it must be collected, concentrated, and refined in order to acquire a high value.
The United States and foreign mineral processing companies use electronic scrap from computer circuit boards for two reasons: (1) it has a high precious metal content and (2) it contains much lower levels of deleterious elements common to ores, such as arsenic, mercury, and, especially, sulfur. These elements can contribute potentially harmful atmospheric emissions (Rob Bouma, Noranda, Inc., oral commun., 2000) and could result in additional costs for recovery and disposal. Military electronic scrap, mostly computer circuit boards, received from the former Soviet Union (Nadeau, 1999) are especially sought for recycling because of their comparatively high precious metal content. The scrap can contain 10 times the amount of precious metals than mined ores and significantly higher amounts of precious metals as electronic components produced elsewhere.

In the mid-1980's, one of the world's largest mining companies, Noranda, Inc. (Noranda) of Canada, investigated ways to make their smelters more profitable. Feasibility studies and testing determined that "mining" computer and other electronic scrap would bring a welcome supplement of copper and precious metals to their smelters. Noranda's findings indicated that the concentration of some metals in average computer and other electronic scrap may be more than twice that found in ores.

So in 1984, Noranda began processing small amounts of scrap (Reid, 1999) and, by 1999, was the largest electronics recycling plant in North America, receiving more than $50,000 \mathrm{t} / \mathrm{yr}$ of electronic scrap from 300 to 400 suppliers in 18 countries (Nadeau, 1999; Reid, 1999). Recyclable materials are considered to be an important feed for Noranda's smelters, as essential as ore concentrates are to the operation's profitability (Rob Bouma, Noranda, Inc., 
written and oral commun., 1999). In order to treat electronic scrap more efficiently, a subsidiary of Noranda in California entered into an agreement with the Hewlett-Packard Company. Hewlett-Packard provides approximately 1,400 t of obsolete PC's and other computer-related electronic scrap to Noranda for recycling on a monthly basis (Reid, 1999). After the computers are dismantled and the components are separated and tested, the useable components are sold, and the shredded metals are separated to be sold as scrap or transported to Noranda's smelters in Canada. Hewlett-Packard pays Noranda for this service and, in return, is assured that components with toxic materials are treated legally, thus avoiding potential liability (Reid, 1999). Hewlett-Packard reuses or recycles nearly 1,600 t or 99 percent by weight of materials received from its customers and company operations.

Major electronic companies also recycle. IBM operates ten materials recovery plants around the world. In 1997, these operations processed more than $62,000 \mathrm{t}$ of manufacturing scrap equipment, obsolete IBM machines, and customer-returned equipment. More than 90 percent was recycled and less than 5 percent was sent to landfills (Amore, 1999).

\section{Plastics}

Plastics derived from computer casings can be reused to house different electronic devices, melted down for use as raw materials for new products, or used as fuel. More than $6,500 \mathrm{t}$ of plastic were reportedly recovered from U.S. electronics recyclers in 1998, an increase of nearly 25 percent over 1997 (National Safety Council, 1999). When used as a fuel for cement kilns in the smelting process, $1 \mathrm{t}$ of plastic can replace nearly $1.3 \mathrm{t}$ of coal (National Safety Council, 1999). The plastic components are consumed at a very high temperature and when mixed with oxygen-enriched air aids the combustion process. Using plastic in this way conserves space in landfills and decreases the use of coal. However, truly effective recycling of plastics from computers is hampered by two things: the variety of plastics used and a lack of labeling. Mixtures of recovered plastic have little value; however, if the plastics are cleaned and separated, prices can range from $\$ 265 / \mathrm{t}$ for flaked polypropylene to $\$ 900 / \mathrm{t}$ for pelletized ABS (acrylonitrile-butadienestyrene).

\section{Glass}

Glass, primarily from cathode ray tube (CRT) monitors, represented about 25 percent of the total weight of material produced by electronics recyclers in 1998, or about 13,200 t (National Safety Council, 1999). Because of its lead content, glass is classified as

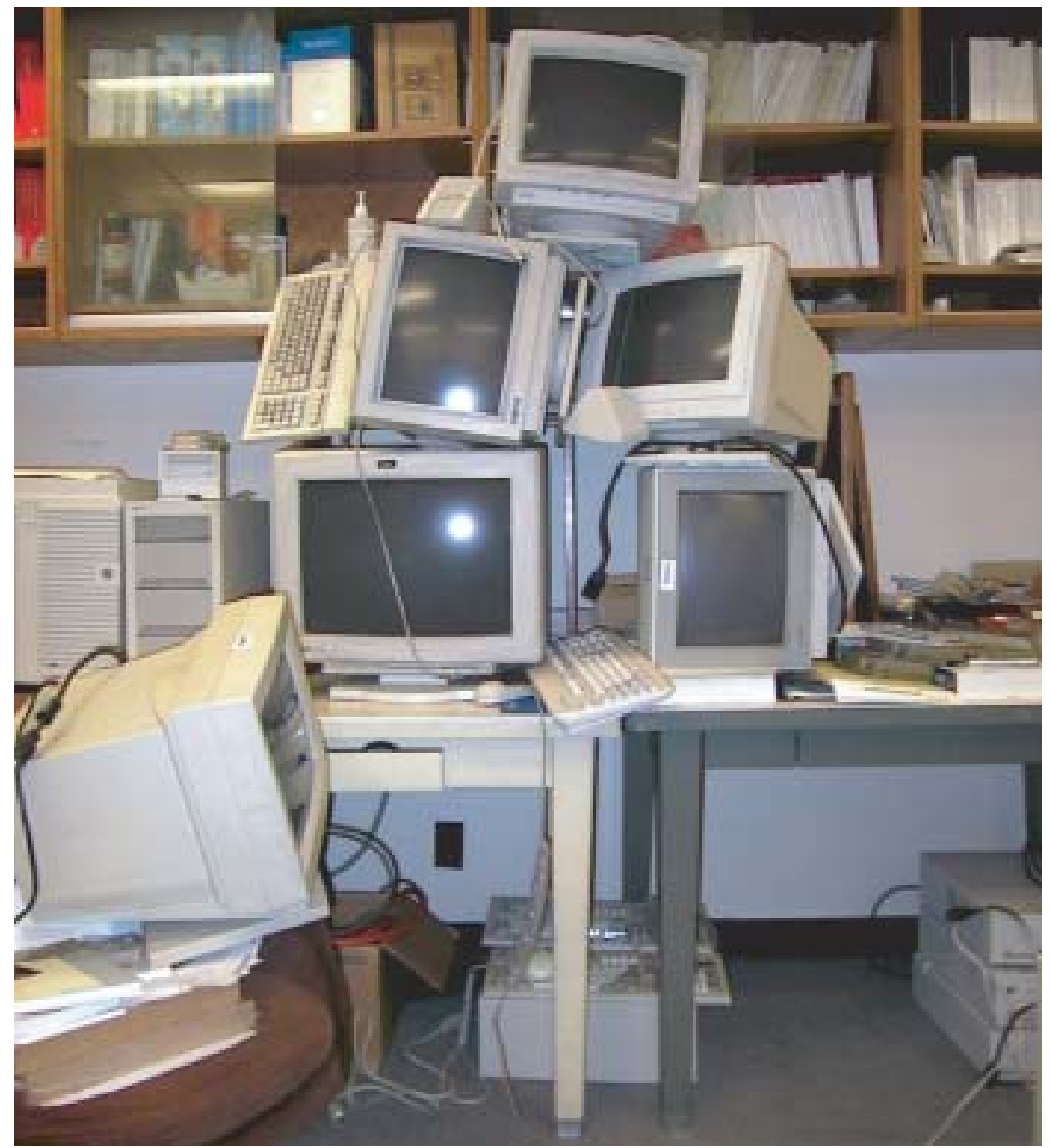

Figure 3. Obsolete computers and monitors, which could be donated, recycled, or remanufactured, accumulate in office storerooms.

hazardous waste, and it must be handled, processed, and disposed of in a manner consistent with federally mandated guidelines.

In 1998, nearly 1.8 million monitors were collected in the United States for recycling or remanufacturing (fig. 3), about 60 percent of which were exported for this purpose (National Safety Council, 1999). Broken glass from monitors is purchased by several companies for the production of new CRT's. Noranda recycles more than $1,000 \mathrm{t}$ of monitors, CRT's, and broken glass from CRT's per year (Rob Bouma, Noranda, Inc., oral commun., 1999). Whole monitors are fed to the company's copper smelter in Quebec. These monitors may contain between 4 and 7 percent copper, between 5 and 10 percent lead, approximately 30 percent silica (the chief component of the glass in CRT's), in addition to other material (primarily plastic from the plastic casings).

CRT's also are recycled. They have between 10 and 13 percent copper, between 15 and 20 percent lead, and between 50 and 60 percent silica. The copper is recovered and converted into a saleable metal at Noranda's metallurgical facilities in Quebec. The silica contained in the glass CRT's has value because silica is required as a fluxing agent in the metals separation process. The silica ultimately combines with slag, an iron-silicate waste product. The lead in the glass is not currently recovered and also is contained in the slag. Because the slag is highly inert and stable, it does not leach lead (Rob Bouma, Noranda, Inc., oral commun., 2000). The silica recovered from the glass CRT's replaces purchases of equivalent amounts of silica.

Clean CRT glass (crushed/broken with the steel and plastic removed) is sent to Noranda's lead smelter in New Brunswick. The facility treats about 200,000 t of lead ore concentrates annually. A large percentage of the lead contained in the glass is recovered, and the silica is consumed in the process as a fluxing agent (Rob Bouma, Noranda, Inc., oral commun., 1999).

In Canada, if the monitors or CRT's are shredded or broken, they are classified as hazardous waste. As such, this material must have formal import approval from the Canadian Government and must be shipped under a Canadian Federal waste manifest. 
Although there is value contained in the monitors and CRT's, the handling costs require Noranda to charge a net fee for recycling the materials. The fee depends on a number of factors, including the form of the material (whether whole monitors, CRT's with or without copper yokes attached, shredded or unshredded, steel removed, and so on), the type of packaging, the mode of delivery, and the lot size. The fee is normally several hundred dollars per metric ton. In 1998, approximately 100,000 monitors were shipped to smelters in the United States (National Safety Council, 1999). Over the next decade in the United States, the amount of glass may decrease and the amount and types of other materials recovered from monitors will change as displays using liquid crystal technologies gain popularity.

\section{Barriers and Opportunities}

In the United States, between 14 and 20 million PC's become obsolete every year. About 75 percent of these obsolete computers are not discarded because their owners perceive them to be valuable (Goodrich, 1999). Eventually, most of these computers will end up in municipal landfills because consumers don't know how best to dispose of them. Currently, more than 10 million PC's, workstations, and mainframes are being added to landfills annually, exceeding $135,000 \mathrm{t}$ of material. This potential supply is of great interest to recyclers.

Recycling (including reuse) reduces the need for new materials. Consequently, less energy is consumed, the amount of potentially toxic material destined for landfills is reduced, and there is less disruption to the environment. The reuse of components and refurbishment of computers lengthens their life spans and, when part of donation programs, provides inexpensive learning tools for students.

Currently, the most effective way to recycle computers is through manufacturers, such as Hewlett-Packard. Most businesses, however, must arrange to have their discarded computers handled by electronics recycling firms and (or) hazardous waste facilities. Computer monitors and other computer components, such as lithium batteries, are separated out by the electronics recycling businesses, are usually considered to be hazardous waste, and, as a result, cannot be placed in municipal landfills. Therefore, computer recyclers in the United States are typically classified as hazardous waste handlers. A number of hazardous waste regulations apply to computer recyclers, which significantly increase operating costs and the overall costs of recycling (Jung, 1999). Additionally, as PC technology continues to evolve, the amount of precious metals used in components is decreasing; as a result, computer parts are worth less. Processing scrap that has lower value coupled with increasing labor, plant, and regulatory costs could have a profound influence on the current structure of the electronics recycling industry, potentially resulting in decreased recycling.

On the other hand, recycling may increase as more and more people recognize the value of recycling. Picking up individual computers by recyclers is not economically practical because it's too expensive and participation is too low. However, centralized collection sites at electronic superstores and curbside pickup on specific dates have shown promise. Computer leasing programs also offer potential for increasing recycling and reuse rates. Other approaches under consideration include requiring returnable deposit fees when purchasing a new computer, take-back programs that require retailers or manufacturers to retain responsibility for end of use, and landfill bans.

Legislators, companies, governmental organizations, public interest groups, and universities have been working on ideas to reduce the amount of waste generated from obsolete computers and electronics and also increase rates of recycling. These ideas include improving the ability to upgradethereby extending the useful life of a computer-and improving the ability to efficiently dismantle and separate the various components. Examples could include consistent use of types of screws, labeling the plastics, and eliminating toxic materials wherever possible. The Environmental Health Center, a division of the National Safety Council, provides information on obsolete computers, including a list of recyclers. It is available from the World Wide Web at http://www.nsc.org/ehc/epr2/donate.htm

The Environmental Issues Council of the Electronic Industries Alliance has organized the Consumer Education Initiative to inform consumers about recycling and reuses of used electronics, including computers. An extensive list of recyclers, by State, is offered at their website. It is available from the World Wide Web at http://www.eiae.org/

\section{References Cited}

Advanced Recovery, Electronic equipment recycling. (Accessed on the web on January 5, 2000, at http://www.advancedrecovery. com/environmentalissues $/ \mathrm{html} /$ electronic equipment_recycling.html)

Amore, Dawn, 1999, Study finds computer recycling not clicking: Waste Age, v. 30, no. 12, p. 13-14.

Broughton, Anne, 1996, Electronics recycling-Circuit board recycling increases: Recycling Today, v. 34, no. 5, May, p. 68-105.

Goodrich, Melissa, 1999, Electronics recycling-Making electronic recycling connections: Recycling Today, v. 37, no. 9, September, p. 64-89.

Hamilton, D.P., and Takahaski, Dean, 1996, Scientists are battling barriers in microchip advances: Wall Street Journal, December 6, 1996, p. A1.

Jung, Leah, 1999, The conundrum of computer recycling. (Accessed on the web on January 5, 2000, at http://www.vista. simplenet.com/conundrum.html)

Nadeau, Jean, 1999, Mining the wreckage of the computer age: Canadian Mining Journal, v. 120, no. 2, April, p. 11-13.

National Safety Council, 1999, Electronic product recovery and recycling baseline report, recycling of selected electronic products in the United States: Washington, D.C., National Safety Council's Environmental Health Center, 47 p.

Porter, J.D., 1998, Computers and electronics recycling challenges and opportunities: Resource Recycling, v. 17, no. 4, April, p. 19-22.

Reid, Robert, 1999, High tech, low grade recycling: Scrap, v. 56, no. 3, May, p. $76-80$.

Veldhuizen, Hennie, and Sippel, Bob, 1994, Mining discarded electronics: UNEP Industry and Environment, v. 17, no. 3-4, July-September, p. 7-11.

For additional information, please contact:

Donald Bleiwas

Telephone: (303) 236-8747, ext. 340

E-mail: bleiwas@usgs.gov

$\boldsymbol{o r} \square$

Thomas Kelly

Telephone: (303) 236-8747, ext. 269

E-mail: kellyt@usgs.gov

U.S. Geological Survey, MS 750

Denver Federal Center, Box 25046

Denver, CO 80225

$\boldsymbol{o r} \downarrow$ visit the Minerals Information home page at http://minerals.usgs.gov/minerals

or contact the Minerals Information Team at (703) 648-4911 